This item was submitted to Loughborough's Research Repository by the author.

Items in Figshare are protected by copyright, with all rights reserved, unless otherwise indicated.

\title{
Understanding cultures, and IFLA's freedom of access to information and freedom of expression (FAIFE) core activity
}

PLEASE CITE THE PUBLISHED VERSION

PUBLISHER

(C) Emerald

LICENCE

CC BY-NC-ND 4.0

REPOSITORY RECORD

Sturges, R. Paul. 2019. "Understanding Cultures, and Ifla's Freedom of Access to Information and Freedom of Expression (FAIFE) Core Activity”. figshare. https://hdl.handle.net/2134/562. 
UNDERSTANDING CULTURES,

\title{
AND IFLA'S FREEDOM OF ACCESS TO INFORMATION AND FREEDOM \\ OF EXPRESSION (FAIFE) CORE ACTIVITY
}

\author{
Paul Sturges \\ Chair of the IFLA FAIFE Committee \\ (Freedom of Access to Information and Freedom of Expression), and \\ Professor of Library Studies \\ Department of Information Science \\ Loughborough University, UK.
}

Published in: Journal of Documentation, 61(2) 2005, 296-305.

\begin{abstract}
The sheer difficulty of entering into the minds of people from different cultures is frequently undervalued, when it is exactly the differences between modes of perception, belief, communication and behaviour that are significant. The need in information and library services for multicultural communities is often described as if it is solely for members of minority communities to be able to obtain materials in their own languages and cultural traditions. The assumption is that existing services provide all that is necessary for them to begin to understand the host community. A more considered view would stress the need for access to richly informative resources so that all members of a multicultural society can move towards a deeper understanding of each other. IFLA's FAIFE initiative may seem to be simply a campaign against the suppression and censorship of information and communication. In fact its implications go much deeper and have a close relationship with Kay Raseroka's IFLA Presidential theme for 2003-5 'Libraries for Lifelong Literacy'. True free access to information is skilled and discriminating access that enables the searcher to locate, identify and interpret information. This is access unhindered by prejudices, misconceptions and inadequate competences. FAIFE's role in facilitating removal of restrictions, combating suppression of information, fostering rights of access and supporting the development of information competences in all communities and in the information professionals who serve them, is potentially a major contributor to the enhancement of fair and harmonious relations in multicultural communities.
\end{abstract}

\section{INTRODUCTION}

There is one way to understand another culture. Living it. Move into it, ask to be tolerated as a guest, learn the language. At some point understanding may come. It will always be wordless.

Peter Hoeg, Froken Smillas Fornemmelse for Sne. 1992 
If, as library and information workers, we seriously want to understand and serve people, whatever their culture, Hoeg's advice (put into the mouth of Miss Smilla) may be rather too demanding. We can, however, achieve a great deal with a less than perfect understanding of any one culture, if we approach service to people of other cultures in a suitable way. The starting point is to recognise the dimensions of cultural difference. First of all, it is essential to make the distinction between biological and cultural differences. When people emphasise the oneness of humanity with phrases such as 'We're all the same really' or 'We are all human underneath the skin' they are recognising our biological unity as a species. Apart from some comparatively minor factors such as skin colour, types of hair, facial features and body shapes, there is very little to distinguish one human from another. This definitely applies to brain size and configuration where, despite the attempts of racist physiologists to argue otherwise, there is no worthwhile evidence of any differences. In the essentials of human behaviour such as choosing partners, caring for children, and the everyday relations with family and neighbours there is also much more in common between all humans than there are differences. The mistake comes if this argument is extended to culture, and it is to the functioning of culture that we need to look for an indication of the role of information.

\section{CULTURE AND INFORMATION}

Culture is responsible for the striking contrasts that can be observed between the behaviour of people from different communities and it is a mistake is to underestimate the strength and depth of cultural differences. To someone from the northern industrialised countries, it may be possible to assume that it is the generally accessible culture of print and other media that matters. We generally prefer not to recognise the possibility that our own mentalities and attitudes were actually culturally constructed in a pre print mode. We prefer to see ourselves as autonomous actors in a world of cultural choices. This compounds our unawareness of the way in which our own identities are products of our culture, and we allow that culture to be hidden to a great extent under the shelter of 'normality'. Yet if we travel with our eyes and minds open, we place ourselves in a position to observe and appreciate cultural difference in parts of the world where cultural distinctiveness is much more something that is openly on display and therefore much better understood.

To take a very striking example, isolated communities in the Sahel region of Africa have cultural beliefs and practices that can defy the logic of 'scientific' observation. To be more precise there are animist communities that live in very close connection with the crocodiles that are the major object of their religious devotion. The ability of small populations of crocodiles to survive in the dry and inhospitable conditions of the region is probably both the reason for people's reverence for them and, in turn, partially the practical product of the same reverence. People have come to make a close mental association between the ability of crocodiles to survive in the water of small and vulnerable creeks and pools and the survival of those vital water sources themselves. The people conserve the water, revere the animals that share the water with them and feed and protect them accordingly. This results in a respectful and comfortable relationship between crocodiles and people that utterly subverts the outsider's view of the crocodile as a vicious and calculating killing machine to be 
feared and avoided at all costs. When you have walked amongst full-grown crocodiles, whilst community members who clearly respect and understand these close neighbours explain their character and behaviour, you begin to have a stronger grasp of the distinctness of cultures and the practical consequences of this.

Yet, of course, there are barriers to such understanding. We cannot all be travellers and not all travellers open their minds to a fuller understanding of what they see. Indeed, we spend much of our time hindered in various ways from coming to a better understanding of people from other cultures. Language is obviously capable of being the most significant of those hindrances. Language carries within it the complexity of culture, and coming to an understanding of what is meant by anything that is said or written is not a simple matter of direct translation. What the individual at the perilous interface between cultures needs is both a strong grasp of language and appropriate information to contextualise and interpret it effectively.

The traveller and the traveller's hosts, migrants and the majority communities they live amongst, and citizens of countries with old-established mixtures of cultures are all in need of rich and helpful information resources. Information offers at least four levels of assistance:

- Facilitating good manners, and therefore helping to begin good relations, as well as avoiding offence and embarrassment;

- Building respect (though not necessarily endorsement of every manifestation of a culture);

- Permitting engagement through exchange of informed views, recognition of enrichment through cultural diversity, and willingness to accept change;

- Offering opportunities for the protecting and championing of cultures.

The role of the librarian is to make sure that through the provision of appropriate materials and services in an open and welcoming environment (real or virtual) these processes are more likely to take place. Before this line of argument can be taken much further, we need to ask ourselves how the library profession has generally seen its role in a multicultural society.

\section{MULTICULTURAL LIBRARIES}

In last decades of the twentieth century, many of the countries with advanced economies embraced multicultural values as a major element of national policy. Multiculturalism tends to focus on the enrichment of society as a whole through the expansion of cultural horizons, and differs somewhat from social inclusion policy, which will be discussed later. The latter is much more concerned with the creation of policies to combat the exclusion of a range of groups, not necessarily defined and identified by culture. The changes that this brought to schooling, employment and welfare policies were also reflected in libraries. Britain is almost certainly not the best example to describe, but the progress of the multicultural project there is nevertheless interesting. All of 25 years ago Clough and Quarmby (1978) carried out the first major research project in the country on public libraries and ethnic minorities. They found initiatives within the public library system to reach out to minority communities, but more often they found that a network of self-help organisations 
within those communities performed information and advice functions that might have been expected of public libraries. Some of these organisations had a certain amount of dialogue with the public libraries, but essentially public library engagement with minorities was fairly limited. Clough and Quarmby's recommendations included the building of partnerships between the public library services and the community organisations. They also recommended more concentration on training in appropriate competences for new librarians. The report was widely discussed at the time it appeared, but Margaret Thatcher was elected to power the year after and official attention shifted in quite another direction.

This does not mean nothing was done. Progressive library services in many parts of the country acquired relevant materials, hired specialist librarians and organised cooperation with the minority communities. But when Elliott (1984) carried out a somewhat similar survey in London a few years later, she found the situation little changed at the policy level and she made a very similar set of recommendations. There was progress in the following years and what such progress might mean can be shown by an example. Libraries serving Chinese communities came to realise that access to their collections was limited by the lack of Chinese OPACs. Thus, in the 1990s catalogue information on a collection of over 50,000 Chinese publications and 10,000 audiovisual items at Westminster's Charing Cross Library could not be accessed online and entries were expressed in English transliteration using the Pinyin system. Seatwo (1999) describes the development of an OPAC for the Chinese collections at Liverpool City Libraries using Chinese characters. The system that has been developed not only allows the user to identify documents in the collections but also includes a community information feature for the Chinese community.

Such examples of progress did not, however, change the basic pattern. When Roach and Morrison (1998a) produced a third general report at about the time the new Labour government came to power, the content was strikingly similar to its predecessors. They found that information users from minorities still preferred to use organisations outside the official domain. Their recommendations followed roughly similar lines to those of the previous reports, but they did provide something extra in the form of a manual of good practice (Roach and Morrison, 1998b). Most importantly, they described some implications of the introduction of computerised services for ethnic minority communities. Yet, the overwhelming sense was that there had been little underlying change over the period. There was also a good deal of frustration within the public library departments serving minorities. Dutt (2001), for instance, drew attention to the uneasy position of ethnic minority librarians in the public libraries - tending to be marginalized and often the victims of cost-cutting exercises. The pessimistic implications of this are to some extent balanced out by evidence of positive approaches to the question of information services for ethnic minorities from slightly different directions.

\section{SOCIAL INCLUSION AND LIBRARIES}

A new emphasis on combating social exclusion (whether arising from class, poverty, race, gender, disability or other form of discrimination) through library and information services was introduced in the UK at about the beginning of the new century. The UK Department for Culture, Media and Sport (1999) set out policy guidelines for libraries on social inclusion and these naturally have considerable 
implications for cultural minorities. Thus Muddiman et al. (2000) provided abundant data on the information environment for not only ethnic minorities, but also people with disabilities, the old, the young and the unemployed. The report engaged with the possibility that information technology might not make things better for informationseekers from minorities, but worse. It showed that libraries have made enormous progress in setting up a network of physical access to ICT facilities, but questioned whether this was having a real impact amongst the socially excluded. The most successful initiatives were shown to be outreach activities of a familiar kind, connecting with communities on their own terms and often on their own ground. Dutch and Muddiman (2001, p193) conclude that "If libraries are to reach out to the excluded of the information society, they will need to move beyond passive conceptions of access and utilise ICT as a means towards a much more active engagement with local communities and disadvantaged users." What we find here can be read as the latest evidence that library engagement with minority cultures in Britain continues to be mainly an attempt to equalise the services available.

Performance in any other country can be judged against this, but comparison might suggest that this persistent, if only partly effective, attempt to engage with the information needs of cultural minorities could actually be seen as comparatively successful. If one were to look at France for example, the pursuit of 'republican' values has been the source of a cultural homogenisation that has trampled on the country's ancient minority languages (Breton, Flemish, Catalan, etc) and attempted to rip the hijab from the heads of young Muslim women. What is most important about the British story, however, is that even if it contains elements of success, it still cannot be claimed to meet the aspiration, sketched out earlier in this paper, of transforming relations between cultures through better information. The minorities cling to services provided by voluntary organisations from within their own communities, whilst the public libraries struggle with mixed effect to serve them better. What is conspicuously missing is a successful campaign to inform all, majority and minority, about each other through the library, and in this way to contribute to harmony and social enrichment. The vision that informs such a campaign is not wholly lacking, but there is a considerable need for the development and assertion of the idea of information service as the agent of improvement.

\section{THE FAIFE INITIATIVE}

What FAIFE offers is a major contribution to precisely the vision that is needed for successful multiculturalism in the libraries of the world. Yet at first sight freedom of access to information may seem to refer to something slightly different. It is therefore worth spending some time at looking at what FAIFE actually stands for. The FAIFE Committee and Office date from 1997 when an IFLA resolution was adopted at the annual Congress in Copenhagen. Since then the Office has received core funding from Danish and other, mainly Scandinavian, sources. It is based in Copenhagen and from there it monitors the state of intellectual freedom within the library community worldwide, often in cooperation with other international human rights organisations, and responds when violations of freedom are identified. It collects and disseminates relevant documentation with the aim of stimulating dialogue, maintains Internet pages, produces an informative annual report, and promotes intellectual freedom policies within IFLA. It also has a programme of contributions to conferences, 
seminars and workshops, for some of which it is the organiser or co-organiser. The international library community has quickly come to recognise the effectiveness of FAIFE's activity in placing intellectual freedom firmly on the professional agenda. Many regard FAIFE as IFLA's most important core activity.

FAIFE's work is rooted in the belief that freedom of thought and opinion, often referred to as intellectual freedom, is a fundamental of a just society. This idea was perhaps most prominently expressed in the UN Universal Declaration on Human Rights, promulgated in 1945, which extended the idea of intellectual freedom to include the right to seek, receive and impart information and ideas. Expressed in this way it becomes completely clear that it provides a theoretical basis for all professional work with information. The principle has long been recognised by IFLA, which promoted it in the form of the idea of Universal Availability of Information (UAI) in the 1980s. This was intended to subsume the narrower, but in practice more or less identical concept of Universal Availability of Publications (UAP), which has since continued to be a major contribution of IFLA to the practical realisation of freedom of access to information. Although UAP may seem a rather unsatisfactory way of expressing freedom of access to information, it does have a certain advantage. This is that it avoids the confusion resulting from the natural abbreviation of the slightly clumsy 'freedom of access to information' to 'freedom of information'.

The point here is that 'freedom of information' is now the accepted way of referring to a rather narrower concept - a statutory right of access by the public to official information. Laws of this type arise from the idea of open government, which includes public rights to observe meetings, consultation on planning and transparency in decision-making. Statutory freedom of information rights have existed in Sweden since 1766 and in a number of other countries from the late twentieth century. The US Freedom of Information Act was passed in 1966 and Britain did likewise in 2000. The UK Act, giving the public access to information held by thousands of 'public authorities' will, however, not come into force until the beginning of 2005. Libraries, except those that hold documentation generated by a public authority of which they form part, do not have a formal role in the structures of freedom of information law. Despite this, because of the expertise of librarians in handling documentation and dealing with enquiries, they are being drawn into formal freedom of information procedures and will no doubt become more important as the practice of seeking information by this route takes a hold on the public mind.

All of that comes within FAIFE's area of interest, but FAIFE's work includes:

- the struggle against formal and tacit censorship;

- resistance to the excessive use of national and official secrecy;

- the questioning of suppression of information for private and corporate reasons;

- identifying and countering restrictions on information flows that create information-poor countries, regions, classes, social groups and individuals;

- discouraging the perpetuation of ineffective and restrictive practices in library work.

The last of these deserves explanation. (Sturges, 2001) If ordinary citizens ask librarians for assistance, they may very well find that this assistance is eagerly forthcoming. On the other hand, they might quite possibly find just the converse to be 
true, with grudgingly limited cooperation. The levels of assistance offered may well seem to depend on the librarian's assessment of how strong or real the enquirer's need for the information might be. Is the enquirer a child seeming to need protection from controversial material, or an old person assumed to prefer unchallenging material, preferably in large print? Does the enquirer appear to have a limited educational background and possible difficulties in coping with highly specialized language and complex explanation? Is the enquirer a woman, 'obviously' more likely to prefer recreational reading than anything technical? Or is the enquirer a highly educated, articulate and confident professional (man) who clearly has a 'need to know'? And, finally, is the enquirer a member of some minority, to be dealt with according to some special set of rules, written or unwritten?

Do such questions and assumptions lurk in the back of librarians' minds? It would be unrealistic to deny that often they do, and when they do, they are a considerable hindrance. This is why Kay Raseroka's IFLA presidential theme for 2003-5 'Libraries for Lifelong Literacy' is so relevant to FAIFE. True free access to information is skilled and discriminating access that empowers the searcher to locate, identify and interpret information so that it can be used to develop real understanding. This is access unhindered by prejudices, misconceptions and inadequate competences. Pantry (1999) identifies four 'conditions for community'. These are:

- Communication skills (listening, summarising, connecting)

- Process skills (negotiating, lobbying, mediation, facilitation)

- Information handling skills (researching, writing, multi-media, web creation)

- Informacy (information awareness, accessing information, using information).

Together they form a set of competences relevant to information professionals, community workers, and individual members of communities. True freedom of access depends on the widespread availability of these skills and this is nowhere more true than when thinking of multicultural communities. By promoting lifelong literacy, or the conditions for community of which Pantry writes, information services offer users command over their own access to information.

\section{FAIFE AND MULTICULTURALISM}

Where FAIFE's principles and activities intersect most clearly with multiculturalism is precisely the area of positive attention to library practice as an expression of true commitment to freedom of access. One way in which this has expressed itself is the struggle against the filtering and blocking of Internet content and communication by libraries with public access points. This is an important, though complicated, issue on which it is vital that librarians receive a clear lead from their professional organisations. Such leadership has come from various sources, for instance, the American Library Association has campaigned vigorously, the Council of Europe (2001) has devised guidelines intended to assist in everyday practice with public access, and FAIFE has consistently provided a strong voice for freedom. Filtering is not, however, an issue independent of others. To filter, you must monitor use and monitoring use requires a suspension of the right of privacy that libraries have traditionally offered to their users. (Sturges, Teng and Iliffe 2001) This may not seem to present a problem for any honest, law-abiding citizen, but frankly even honest and law-abiding citizens find that their rights are harder to establish if they are obviously 
members of some minority group. The frequency with which some drivers are stopped by the traffic police for 'routine' checks on their driving documents suggests that there may even be a little-known offence of 'driving whilst black'. Internet use whilst a member of a minority might well be seen by some as a similar offence.

It is a simple matter of fact that recent immigrants, migrant workers, traveller communities and the Roma, asylum seekers, and refugees (not to mention battered wives, abused children, and other weak and vulnerable members of society) do not feel comfortable using communication facilities (such as the free email provided by many libraries) if they are required to provide identity to do so. Anonymity is a natural condition of freedom in this context. This is why the draconian security measures adopted by governments in the aftermath of the 9.11 attacks in the USA are such a source of disquiet to librarians. Measures such as the USA PATRIOT Act and the UK Anti Terrorism Act, both of 2001, require the retention of transaction data and its possible surrender to police and security services. It is arguable that such measures are more capable of sweeping up the innocent and well intentioned than the guilty (who will take precautions to conceal their identities and activities). It is also worth mentioning in passing that the Convention on Cybercrime, which most European countries and a few prominent countries from outside Europe signed in 2001, offers the potential to facilitate this type of approach by providing a basis of international cooperation. All of these trends (against which FAIFE stands) serve to emphasise the point that good freedom of access practice is also based on good privacy practice.

\section{THE PARADOX OF FREEDOM OF EXPRESSION}

Finally, it is necessary to point out that FAIFE also offers challenges as well as answers and guidance. The principle of freedom of expression is there in FAIFE's name because it is inseparably linked with freedom of access. The basic statements on these principles, such as the First Amendment to the American Constitution or the UN's Universal Declaration of Human Rights, are first of all statements on freedom of expression and then, by inference or explicitly, statements favouring freedom of access to information. The problem with freedom of expression is that it is necessary to accept that it means that expression that will disgust, frighten or disturb will also be permitted along with communication that will enlighten and uplift. This is a problem that governments address by identifying certain exceptions, most commonly to protect national security. In some authoritarian societies national security becomes such an enormous concern that it threatens to exclude most of the forms of comment that are permitted in freer societies. Even democratic and enlightened states do, however, find a particular problem with expression of hatred based on racial, religious or other cultural manifestations. In a multicultural society the committed advocate of free expression is faced very directly with this problem.

Is it acceptable to allow the kind of rhetoric that the Nazis used against the Jews, the British National Party uses against Asian Britons, or extremists in many societies use against the Roma, on grounds of freedom of expression? Enlightened people may well support the laws against the incitement of racial hatred that exist in Britain, for example. Even if one decides that permitting the open expression of distasteful and dangerous views is better than their suppression, not least because it can then be the basis of open debate, there is discomfort. The source of discomfort may well be because whilst we wish every culture to learn about others, to respect them and to find 
the means to live in harmony with them, there remains the feeling that there are indefensible elements to all cultures. Certainly mutual understanding between cultures must be expected to change aspects of any one culture, but sadly sometimes the cultural expression that seems most to need protection is that which is most vulnerable to the globalising mediocrity of the Disney/Macdonald culture. What seem able to resist outside influence most stubbornly are cultural practices such as those associated with initiation. Circumcision of boys may not be particularly harmful, merely better avoided, but the sexual mutilation of girl children in the name of culture is surely unacceptable on any grounds. In the end, however, it is the FAIFE position that only through the exercise of freedom of expression and access to information that we can understand, and then come to terms with any aspect of culture.

\section{CONCLUSION}

Very few professionals who have looked at the way in which library services respond to multicultural society are fully satisfied with what they find. The specialist librarians who provide the services, generally drawn from minority communities themselves, certainly tend not to be happy with their own position or what they can offer to those they serve. The obvious way of dealing with this is to give multicultural services a higher policy profile and fund them better. This would certainly have positive effects, but more of the same is not necessarily good enough. Implicit in some of the writing on social inclusion there is a shift of emphasis towards a recognition that the approach to minorities needs to be grounded in more than just a recognition that they need services too. A similar sense that library and information services in a multicultural society need a broader, unifying vision can also be derived directly from IFLA's FAIFE initiative. FAIFE offers a generously defined vision of freedom of access to information that can provide an intellectual basis for planning and designing services. An emphasis on informacy to empower uses from all communities, respect for anonymity and privacy of use, and facing up to the problems of freedom of expression all stem naturally from this vision. It offers an approach that avoids the ghettoisation of information services on the one hand, and the homogenisation of cultures on the other. Research and innovative practice in information services for multicultural societies need the underpinning of principle that the freedom of access to information idea, as articulated by FAIFE, offers.

\section{REFERENCES}

Clough, E. and Quarmby, J. (1978) A public library service for ethnic minorities in Great Britain. London: Library Association.

Council of Europe (2001) Public access and freedom of expression in networked information: guidelines for a European cultural policy. Strasbourg: Council of Europe Publishing.

Dutch, M. and Muddiman, D. (2001) The public library, social exclusion and the information society in the United Kingdom. Libri 51, 183-194.

Dutt, K. (2001) Not just black and white. Library Association Record 103 (8) 486-7. 
Elliott, P. (1984) Public libraries and self-help ethnic minority organisations. London: Polytechnic of North London.

Muddiman, D. et al. (2000) Open to all? The public library and social inclusion. 3 vols. (Library and Information Commission Research reports 84, 85, and 86). London: Resource.

Pantry, S. (1999) Building community information networks: strategies and experiences. London: Library Association Publishing.

Roach, P. and Morrison, M. (1998a) Public libraries, ethnic diversity and citizenship. (British Library RIC Report 76). Coventry: University of Warwick, Centre for Research In Ethnic Relations.

Roach, P. and Morrison, M. (1998b) Public libraries and ethnic diversity: a baseline for good practice. (British Library RIC Report 113). Coventry: University of Warwick, Centre for Research in Ethnic Relations.

Seatwo, A. (1999) Chinese OPAC in Liverpool public libraries. New Library World 100 (1151) 254-264.

Sturges, P. (2001) The library and freedom of information: agent or icon? Alexandria 13 (1) 3-16.

Sturges, P., Teng, V. and Iliffe, U. (2001) User privacy in the digital library environment: a matter of concern for information professionals. Library Management $22(8 / 9) 364-370$.

UK Department for Culture, Media and Sport (1999) Libraries for all: social inclusion in public libraries. Policy guidelines for local authorities in England. London:

Department for Culture, Media and Sport. 